\title{
Ancient founder mutation is responsible for Imerslund-Gräsbeck Syndrome among diverse ethnicities
}

\author{
Cameron M Beech ${ }^{1 \dagger}$, Sandya Liyanarachchi ${ }^{1 \dagger}$, Nidhi P Shah ${ }^{1}$, Amy C Sturm², May F Sadiq ${ }^{3}$, Albert de la Chapelle \\ and Stephan M Tanner ${ }^{1 *}$
}

\begin{abstract}
Background: Imerslund-Gräsbeck syndrome (IGS) was described just over 50 years ago by Olga Imerslund and Ralph Gräsbeck and colleagues. IGS is caused by specific malabsorption of cobalamin (Cbl) due to bi-allelic mutations in either the cubilin gene (CUBN) or the human amnionless homolog $(A M N)$. Mutations in the two genes are commonly seen in founder populations or in societies with a high degree of consanguineous marriages. One particular mutation in AMN, c.208-2A>G, causing an out-of-frame loss of exon 4 in the mRNA, is responsible for some $15 \%$ of IGS cases globally. We present evidence that this founder mutation causes a substantial percentage of cases among diverse ethnicities and that the mutation is as old as human civilization.

Methods: Partial genotyping indicated a founder event but its presence in diverse peoples of Arabic, Turkish, Jewish, and Hispanic ancestry suggested that the mutation might be recurrent. We therefore studied the flanking sequence spanning 3.5 $\mathrm{Mb}$ to elucidate the origin of the haplotype and estimate the age of the mutation using a Bayesian inference method based on observed linkage disequilibrium.

Results: The mutation's distribution, the size of the shared haplotype, and estimates of growth rate and carrier frequency indicated that the mutation was a single prehistoric event. Dating back to the ancient Middle East around 11,600 BC, the mutation predates the advent of writing, farming, and the monotheistic religions of the region.

Conclusions: This mutation causes over 50\% of the IGS cases among Arabic, Turkish, and Sephardic Jewish families, making it a primary target for genetic screening among diverse IGS cases originating from the Middle East. Thus, rare founder mutations may cause a substantial number of cases, even among diverse ethnicities not usually thought to be related.
\end{abstract}

Keywords: Imerslund-Gräsbeck syndrome, juvenile cobalamin deficiency, founder mutation, age estimation, mutation screening, anemia, ethnicity

\section{Background}

Imerslund-Gräsbeck syndrome (IGS, megaloblastic anemia 1; OMIM261100) is a recessively inherited childhood disorder[1]. IGS is prevalent in societies where consanguinity is common or in communities that underwent a population bottleneck [2]. The disease is

\footnotetext{
* Correspondence: stephan.tanner@osumc.edu

+ Contributed equally

${ }^{1}$ Comprehensive Cancer Center, The Ohio State University, Columbus, OH 43210, USA

Full list of author information is available at the end of the article
}

manifested by an increased propensity for infections, fatigue, attention deficit, paralysis, and ultimately megaloblastic anemia that can be fatal if left untreated. The primary diagnostic criteria are reduced vitamin $B_{12}$ levels in the serum, elevated homocysteine and methylmalonic acid levels in the blood and urine, and often mild proteinuria [3]. The disorder, which is caused by selective malabsorption of cobalamin ( $\mathrm{Cbl}$; vitamin $\left.\mathrm{B}_{12}\right)$ in the intestine, occurs due to bi-allelic mutations in either the cubilin (CUBN, OMIM602997 [4]) or the amnionless gene (AMN, OMIM605799 [2,5]. The 
proteins encoded by $C U B N$ and $A M N$ form a cellular receptor named cubam found on the enterocytes in the ileum, renal tubular cells, and cells of the yolk sac. In the intestine, cubam facilitates the absorption of $\mathrm{Cbl}$ and other nutrients from the food, and in the kidneys, cubam is responsible for protein reabsorption [6]. Cubam is further required for patterning of the rodent embryo [7] but its role in human development is presently unclear [8]. Interestingly, mutations in the GIF gene coding for gastric intrinsic factor have been implicated in Intrinsic Factor Deficiency (IFD; OMIM261000 [9-11]), a disease with similar symptoms except for proteinuria, which is not seen in IFD. Both IGS and IFD are treatable with life-long parenteral $\mathrm{Cbl}$ supplementation, which alleviates the symptoms except the treatment-resistant proteinuria in IGS [3].

Diagnosing IGS is a time-consuming and often inconclusive procedure mainly based on excluding other causes of $\mathrm{Cbl}$ deficiency, of which there are many [3]. Genetic diagnostics is not widely available and is far from straightforward because of the genetic heterogeneity. We have screened over 150 patients or sibships with recessive hereditary $\mathrm{Cbl}$ malabsorption in the past 10 years $([2,5,10,11]$ and SMT unpublished data). About $80 \%$ were mutated in either $A M N$ or CUBN (causing IGS) or GIF (causing IFD), while the $A B C C 1$ gene was excluded [12]. Early on, we documented four IGS patients from three families (two Turkish and one Sephardic Jewish) with the homozygous splice site mutation c.208-2A>G in intron 3 of $A M N$ [2]. This mutation causes exon 4 ( $88 \mathrm{bp}$ ) to be skipped in the messenger RNA and results in a frameshift that leads to a truncated $A M N$ protein [5]. Limited genotyping suggested that these four patients shared a similar haplotype flanking the mutation [2]. Since then we have identified an additional 16 patients from 13 unrelated families, for a total of 20 patients from 16 sibships, all homozygous for the AMN c.208$2 \mathrm{~A}>\mathrm{G}$ mutation (Additional file 1). Most families were of Sephardic Jewish (4) or Turkish descent (7) but also included Arabic families from Jordan (3). One case from the USA had Hispanic roots but based on the name was judged to be of Jewish ancestry and one case was from Spain without detailed ethnic information. The occurrence of this particular mutation in patients originating mainly from the Eastern Mediterranean supported that c.208-2A $>$ G might be a founder mutation. However, its incidence among these different ethnicities and across a large geographic region challenged that notion. The alternative explanation was that c.208-2A>G was a recurrent molecular defect, arising repeatedly de novo. Given that this mutation is the most frequent cause of IGS outside Scandinavia, clarifying its origin was of clinical importance.

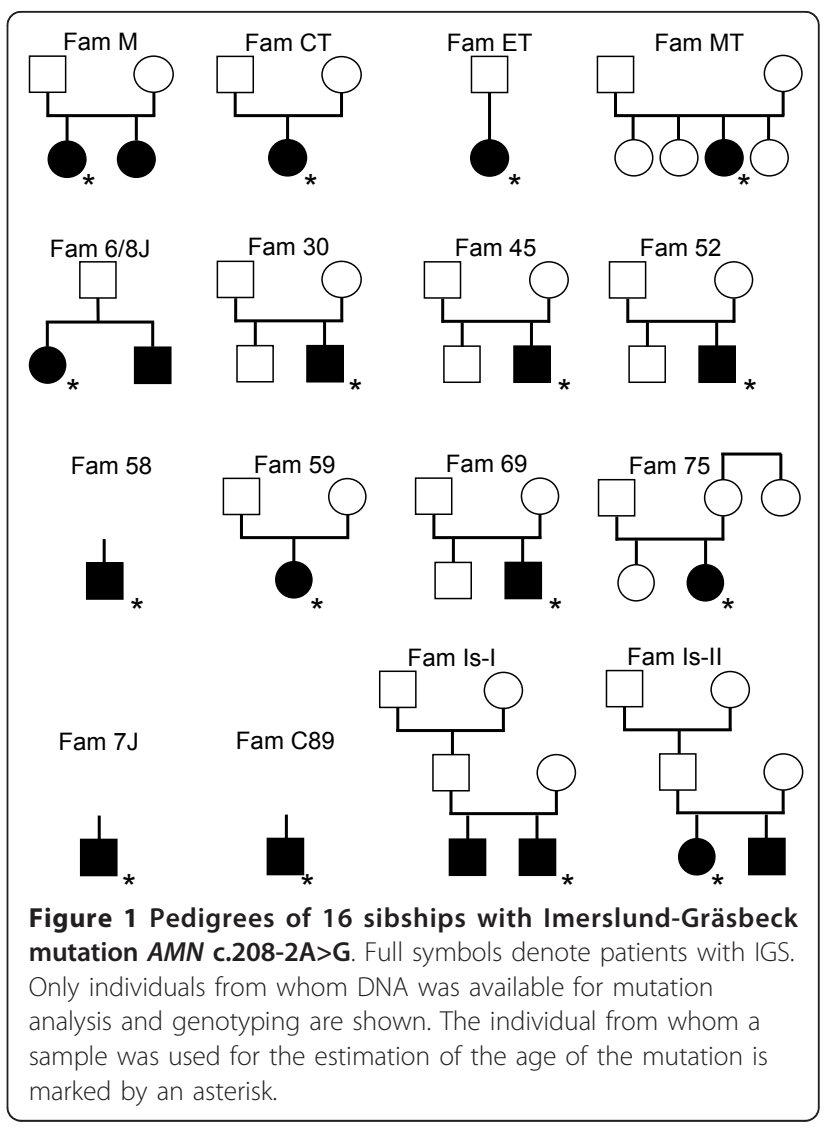

\section{Methods}

\section{Patient samples and controls}

A total of 20 patients with IGS ( 9 female, 11 male, ages 2-19 years when diagnosed), 24 parents, 8 unaffected siblings, and 4 grandparents from 16 IGS families were included in this study (Additional file 1 and Figure 1). Patients with IGS were diagnosed based on established criteria $[1,13]$, while the parents were healthy. All the families were allegedly unrelated. Thirty-six anonymous Jordanian controls (Arabs, ages > 18 years) were obtained from the Department of Biological Sciences, Yarmouk University in Irbid, Jordan.

\section{Mutation screening and genotyping}

Genomic DNA was extracted from white blood cells using standard phenol-chloroform-ethanol precipitation after written informed consent according to institutional review board guidelines of the Ohio State University and the Declaration of Helsinki. Molecular diagnosis involved screening the $A M N$ and $C U B N$ genes for suspected IGS. Individual exons of $A M N$ or $C U B N$ were amplified by PCR and analyzed as previously described [2,5]. After identifying the $A M N$ c.208-2A>G mutation in exon 4, DNA samples from cases and family members were genotyped. 
Flanking markers from 2.3 Mb centromeric to $1.2 \mathrm{Mb}$ telomeric of the $A M N$ locus were genotyped, including 18 microsatellites (AMNM11, AMNM12, D14S1051, AMNM13, D14S577, G35981, AMNM3, AMNM4, D14S272, AMNM5, AMNM6, AMNM7, AMNM1, D14S293, AMNM14, AMNM8, AMNM15, AMNM10) and 11 single nucleotide polymorphisms (rs1211497, rs59793431, rs57687948, rs2295828, rs2295829, rs1190225, rs1190228, rs1190229, c.1169+42S, rs1190233, rs35285749; Figure 2). The microsatellites labeled $A M N M n$ and G35981 were simple-sequence tandemrepeats identified by repeat masker. The microsatellites were genotyped using FAM-labeled primers and the Genotyper program, while the SNPs were typed by SNaPshot (Applied Biosystems, Foster City, CA).

\section{Haplotype construction}

Obtained genotype data were used to construct haplotypes using the linkage program Merlin [14] and the PHASE 2.0 program [15] according to their manuals.

\section{Age estimation}

Mutation age estimate was carried out with the DMLE +2.3 software program [16] using the 29 loci genotyped. In order to do so, the proportion of disease haplotypes sampled and the growth rate were estimated. For the Sephardim, we used an estimate of $\sim 2$ million for its population, while for the Muslim source population we added up Turkey ( 76.5 million) and Jordan ( $\sim 6.5$ million), for a total of 83 million [17]. The proportion of disease chromosomes sampled depended on an estimate of the mutation frequency, which was unknown. Thus, the incidence rate of IGS was estimated at 1 case per $10,000,1: 100,000,1: 500,000$ and $1: 1,000,000$ people for a calculated carrier frequency of the mutation of 1 in 100, 1 in 316, 1 in 707, and 1 in 1,000 individuals, respectively. Turkey has a current population growth rate of $1.24 \%$ and Jordan's is $0.98 \%$ per year [17]. Before 1 AD the annual population growth rate was potentially less than $\sim 1 \%[18,19]$. Thus, for the growth rate a range of values (1-3\%) was used for the calculations in part based on the growth rates by Zelinger and colleagues [20].

\section{Results \& Discussion \\ Mutation haplotype}

The haplotyping results indicated that two almost identical haplotypes carried the mutation. One was found in the 5 "Jewish" families (4 Sephardic and one Hispanic) and the other in the 10 "Muslim" (Turkish and Jordanian) families. The sole Spanish case (patient family 30; Figure 1) carried a "Jewish" and a "Muslim" haplotype. The Jewish haplotype differed from the Muslim haplotype - with a few exceptions - at marker D14S1051 (genotype 182/180), two SNPs upstream of exon 1 (rs2295828, rs2295829), and marker AMNM1 (192/190); i.e. the Jewish haplotype is 182-C-C-192 and the Muslim haplotype is 180-T-G-190 (Additional file 1 and Figure 2 ). At first, this suggested that we observed separate Jewish and Muslim mutational events, in particular because the two SNPs are only $5.8 \mathrm{~kb}$ upstream from the mutation c.208-2A>G. However, the two haplotypes shared all alleles up to marker D14S272, which is 117 $\mathrm{kb}$ centromeric to the mutation, and likewise $60 \mathrm{~kb}$ telomeric to the mutation marker D14S293 delimited a common conserved haplotype. Moreover, alleles from $A M N M 13$ to $A M N M 14$ were by and large identical on both haplotypes, indicating that a mutation protohaplotype of at least $950 \mathrm{~kb}$ was shared (Additional file

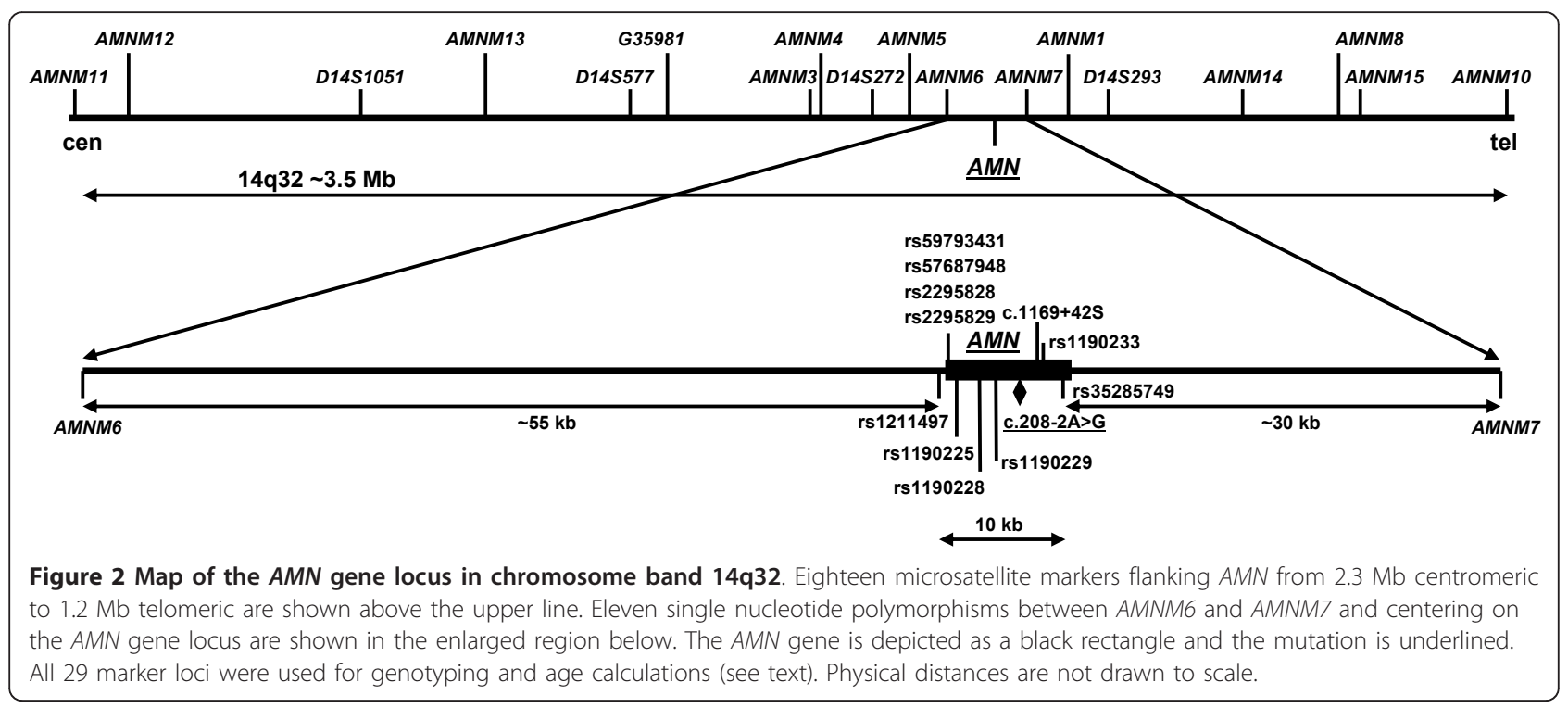


1 and Figure 2). This fact supported the concept that we observed a single mutational event and that the microsatellite markers D14S1051, AMNM1, and the two SNPs (rs2295828, rs2295829) were mutated or recombined later.

\section{Age of the mutation}

We first combined the two ethnic groups for age estimation. Of the 20 patients, 16 (5 Jewish, 10 Muslim, and one compound Spanish case) were unrelated and selected for age calculation, resulting in 32 disease chromosomes. The sum of the populations was 85 million. We also concluded that the frequency of IGS is likely greater than 1 in 1 million; at least among the Sephardic Jews with 5 confirmed patients among $\sim 2$ million people. The 10 cases among 83 million Turks and Jordanians are probably underestimated because of lack of local genetic testing. We noted that four of the ten Muslim cases were diagnosed among expatriates in Europe. Thus, we estimate the IGS incidence for both groups caused by this mutation to be around 1 in 500,000 people for a carrier frequency of 1:707 but we calculated the age for various incidences (Additional file 2). After applying the different growth rates, the age was estimated to be between 8,050 years (95\% confidence interval [CI] 6,450-11,200 years) and 19,225 years (95\% CI: $14,300-28,600$ years) for an average of $\sim 13,600$ years ( 11,600 BC).

If the mutation originated around $11,600 \mathrm{BC}$ it could explain why it is today seen in the peoples of Turkey and Jordan but not necessarily why it is only present in Jews of Sephardic roots. We would expect the mutation to be present in various Jewish groups because of their common roots $[21,22]$. However, to date we have only studied three other unrelated Jewish IGS patients, who were all Ashkenazi. Two of these carried a homozygous CUBN mutation, c.2614_2615delGA; p.D872fs (SMT unpublished data), and one was compound heterozygous for $A M N$ c. $43+1 \mathrm{G}>\mathrm{T}$; splice site \& c.701G>T; C234F [23]. Since Ashkenazim are generally aware of modern genetic research, the absence of the $A M N$ mutation c.208-2A $>\mathrm{G}$ among them suggested that it was never present in their founder population. The lack of c.208-2A $>G$ in other Jewish groups of the Diaspora could have a similar explanation. Consequently, the mutation's exclusive presence among Sephardic Jews suggested that the mutation had entered that Jewish group from a non-Jewish background rather than the other way. When the age calculations were repeated by separating the cohort into Jews ( 2 million and 10 chromosomes) and Muslims ( 83 million and 20 chromosomes) - the mixed case was removed - we estimated the age to be between 4,275 years (95\% CI: $2,875-7,475$ years) and 10,975 years
(95\% CI: 5,525-19,975 years) for the Jewish haplotype and between 7,225 years (95\% CI: 5,600-9,875 years) and 19,000 years (95\% CI: $13,625-26,650$ years) for the Muslim haplotype (Additional file 2). Thus indeed, the Muslim haplotype appeared to be older than the Jewish haplotype. However, the Jewish population was much smaller, thus the proportion of disease chromosomes sampled became greater. This caused the Jewish haplotype to appear younger than it probably is (Additional file 2). The size of the conserved haplotype (when ignoring D14S1051, AMNM1, and the two SNPs rs2295828 and rs2295829) was about the same in both groups $(\sim 1 \mathrm{Mb})$, suggesting a similar age and origin. The alternative explanation of two identical mutational events in Jews and Muslims would have to assume that the mutation occurred twice around the same time, judged from the haplotype size. Moreover, it would have to have affected two almost identical haplotypes. When studying the frequency of the proto-haplotype among 36 Jordanian controls, we detected it only once among 72 chromosomes (Additional file 1). Thus, the probability of two identical mutations occurring around the same time on the same rather rare haplotype is low. In addition, this mutational event has apparently never happened again, thus the evidence was not supporting a mutational hotspot mechanism. In fact, the consistent differences between the Muslim and the Sephardic haplotypes at D14S1051, AMNM1, and the two SNPs rs2295828 and rs2295829 point to single split and no subsequent convergence until today. The "compound heterozygous" Spanish patient (family 30 ) indeed may be the product of Sephardic and later Muslim migration to Spain [24]. The Hispanic case from the USA might also be traced back to the Iberian Peninsula and the expulsion of Jews from there in $1492 \mathrm{AD}$, which also brought them to the New World. Finally, two more IGS cases with this mutation were described in the literature, one from Tunisia, albeit without further ethnic details [25], and another from Austria with Turkish ancestry [26].

The oldest known founder mutation to date appears to be the deltaF508 in the cystic fibrosis gene CFTR that was estimated to be 11,000-52,000 years old depending on genetic (microsatellite mutation rate and selection) and demographic (growth rate and population size) parameters $[27,28]$ but its population origin remains enigmatic [29]. While certain CFTR mutations are hypothesized to convey a selective advantage [30], to our knowledge there is no known benefit for healthy heterozygous carriers of IGS mutations, thus a heterosis effect is unlikely. While the exact frequency of IGS carriers remains unknown, the incidence of IGS is probably higher than one would expect from the carrier frequency because of a high degree of consanguinity. 


\section{Conclusions}

We have used a series of assumptions to estimate the age range of a founder mutation in $A M N$ that causes IGS. Judging the data conservatively, we believe that the region of origin for the mutation to be in Northern Mesopotamia (today's Eastern Turkey and Northern Iraq) some 13,600 years ago, placing it before the beginning of the Neolithic period (ca. 9,500 BC). Its exclusive presence in Sephardic Jews today could be explained by a common ancestor in an early Semitic population whose descendants contributed to that Jewish tribe as well as the Turkish and Arabic populations we recognize today. The natural history of this mutation is in agreement with recent studies that support a common but complex ancestry between Jews and non-Jews in the Middle East [21,22].

Although $A M N$ c.208-2A>G is apparently younger than CFTR deltaF508, it appears to be one of the oldest human disease mutations known to date and clearly occurred first in the Middle East. It causes some 15\% of IGS cases worldwide and more than 50\% among Turks, Jordanians, and Sephardim combined (SMT unpublished data). Given that the genetic analysis for newly diagnosed IGS cases is complex, $A M N$ c.208-2A>G should be considered first when dealing with patients originating from Turkey, Jordan, Spain, Tunisia, or with an ethnic Sephardic background.

\section{Additional material}

Additional file 1: Genotypes of 16 sibships with $A M N$ mutation c.208-2A>G and haplotype information of 36 Jordanian controls Detailed genotype and haplotype data of 29 markers flanking the AMN gene. The mutation haplotypes for Jewish and Muslim patients are identified by color.

Additional file 2: Age estimation with DMLE+2.3 for $A M N$ mutation c.208-2A>G. Age estimation calculations based on various growth rates and carrier frequencies as indicated in the text.

\section{Acknowledgements}

We would like to extend our gratitude to the families and their compassionate clinicians for supporting our research over many years. This work was supported in part by grant CA16058 from the National Cancer Institute, USA.

\section{Author details}

${ }^{1}$ Comprehensive Cancer Center, The Ohio State University, Columbus, OH 43210, USA. 'Department of Internal Medicine, The Ohio State University, Columbus, OH 43210, USA. ${ }^{3}$ Department of Biological Sciences, Yarmouk University, Irbid 21163, Jordan.

\section{Authors' contributions}

CMB carried out the molecular genetic studies and drafted the manuscript. $S L$ designed and performed the statistical analysis and helped to draft the manuscript. NPS participated in the molecular genetic studies. ACS and MFS coordinated DNA sample collection. AdlC commented on the manuscript draft. SMT conceived and designed the study, coordinated the research, and wrote the final manuscript. All authors read and approved the final manuscript.

\section{Competing interests}

The authors declare that they have no competing interests.

Received: 26 September 2011 Accepted: 13 November 2011

Published: 13 November 2011

\section{References}

1. Gräsbeck R: Imerslund-Gräsbeck Syndrome (selective vitamin B12 malabsorption with proteinuria). Orphanet J Rare Dis 2006, 1:17.

2. Tanner SM, Li Z, Bisson R, Acar C, Oner C, Oner R, Cetin M, Abdelaal MA, Ismail EA, Lissens W, et al: Genetically heterogeneous selective intestinal malabsorption of vitamin B12: founder effects, consanguinity, and high clinical awareness explain aggregations in Scandinavia and the Middle East. Hum Mutat 2004, 23:327-333.

3. Gräsbeck R, Tanner SM: Juvenile selective vitamin B12 malabsorption: 50 years after its description - 10 years of genetic testing. Pediatr Res 2011.

4. Aminoff $M$, Carter JE, Chadwick RB, Johnson C, Gräsbeck R, Abdelaal MA, Broch $\mathrm{H}$, Jenner LB, Verroust PJ, Moestrup SK, et al: Mutations in CUBN, encoding the intrinsic factor-vitamin B12 receptor, cubilin, cause hereditary megaloblastic anaemia 1. Nat Genet 1999, 21:309-313.

5. Tanner SM, Aminoff M, Wright FA, Liyanarachchi S, Kuronen M, Saarinen A, Massika O, Mandel H, Broch H, de la Chapelle A: Amnionless, essential for mouse gastrulation, is mutated in recessive hereditary megaloblastic anemia. Nat Genet 2003, 33:426-429.

6. Fyfe JC, Madsen M, Hojrup P, Christensen El, Tanner SM, de la Chapelle A, He Q, Moestrup SK: The functional cobalamin (vitamin B12)-intrinsic factor receptor is a novel complex of cubilin and amnionless. Blood 2004, 103:1573-1579.

7. Strope S, Rivi R, Metzger T, Manova K, Lacy E: Mouse amnionless, which is required for primitive streak assembly, mediates cell-surface localization and endocytic function of cubilin on visceral endoderm and kidney proximal tubules. Development 2004, 131:4787-4795.

8. Pedersen GA, Chakraborty S, Steinhauser AL, Traub LM, Madsen M: AMN directs endocytosis of the intrinsic factor-vitamin $B(12)$ receptor cubam by engaging ARH or Dab2. Traffic 2010, 11:706-720.

9. Yassin F, Rothenberg SP, Rao S, Gordon MM, Alpers DH, Quadros EV: Identification of a 4-base deletion in the gene in inherited intrinsic factor deficiency. Blood 2004, 103:1515-1517.

10. Tanner SM, Li Z, Perko JD, Oner C, Cetin M, Altay C, Yurtsever Z, David KL, Faivre L, Ismail EA, et al: Hereditary juvenile cobalamin deficiency caused by mutations in the intrinsic factor gene. Proc Natl Acad Sci USA 2005, 102:4130-4133.

11. Ament AE, Li Z, Sturm AC, Perko JD, Lawson S, Masterson M, Quadros EV, Tanner SM: Juvenile cobalamin deficiency in individuals of African ancestry is caused by a founder mutation in the intrinsic factor gene GIF. Br J Haematol 2009, 144:622-624.

12. Shah NP, Beech CM, Sturm AC, Tanner SM: Investigation of the ABC transporter MRP1 in selected patients with presumed defects in vitamin B12 absorption. Blood 2011, 117:4397-4398.

13. Broch H, Imerslund O, Monn E, Hovig T, Seip M: Imerslund-Gräsbeck anemia. A long-term follow-up study. Acta Paediatr Scand 1984, 73:248-253.

14. Abecasis GR, Cherny SS, Cookson WO, Cardon LR: Merlin-rapid analysis of dense genetic maps using sparse gene flow trees. Nat Genet 2002, 30:97-101.

15. Stephens M, Donnelly P: A comparison of bayesian methods for haplotype reconstruction from population genotype data. Am J Hum Genet 2003, 73:1162-1169.

16. Reeve JP, Rannala B: DMLE+: Bayesian linkage disequilibrium gene mapping. Bioinformatics 2002, 18:894-895.

17. U.S. Central Intelligence Agency: The CIA world factbook 2011 New York: Skyhorse Pub.; 2011.

18. Durand JD: Historical estimates of world population: an evaluation Philadelphia: Population Studies Center, University of Pennsylvania; 1974.

19. Haub C: How many people have ever lived on earth? Popul Today 1995, 23:4-5.

20. Zelinger L, Greenberg A, Kohl S, Banin E, Sharon D: An ancient autosomal haplotype bearing a rare achromatopsia-causing founder mutation is shared among Arab Muslims and Oriental Jews. Hum Genet 2010, 128:261-267. 
21. Atzmon G, Hao L, Pe'er I, Velez C, Pearlman A, Palamara PF, Morrow B, Friedman E, Oddoux C, Burns E, Ostrer H: Abraham's children in the genome era: major Jewish diaspora populations comprise distinct genetic clusters with shared Middle Eastern Ancestry. Am J Hum Genet 2010, 86:850-859.

22. Behar DM, Yunusbayev B, Metspalu M, Metspalu E, Rosset S, Parik J, Rootsi S, Chaubey G, Kutuev I, Yudkovsky G, et al: The genome-wide structure of the Jewish people. Nature 2010, 466:238-242.

23. Luder AS, Tanner SM, de la Chapelle A, Walter JH: Amnionless (AMN) mutations in Imerslund-Gräsbeck syndrome may be associated with disturbed vitamin B(12) transport into the CNS. J Inherit Metab Dis 2008, Epub Jan 7.

24. Assis YT: The Jews of Spain: from settlement to expulsion Jerusalem: Rothberg School for Overseas Students, Hebrew University: Dor Hemshech Dept., World Zionist Organization; 1988.

25. Bouchlaka C, Maktouf C, Mahjoub B, Ayadi A, Sfar MT, Sioud M, Gueddich N, Belhadjali Z, Rebai A, Abdelhak S, Dellagi K: Genetic heterogeneity of megaloblastic anaemia type 1 in Tunisian patients. J Hum Genet 2007, 52:262-270.

26. Namour F, Dobrovoljski G, Chery C, Audonnet S, Feillet F, Sperl W, Gueant JL: Luminal expression of cubilin is impaired in ImerslundGrasbeck syndrome with compound AMN mutations in intron 3 and exon 7. Haematologica 2011, 96:1715-1719.

27. Morral N, Bertranpetit J, Estivill X, Nunes V, Casals T, Gimenez J, Reis A, Varon-Mateeva R, Macek M Jr, Kalaydjieva L, et al: The origin of the major cystic fibrosis mutation (delta F508) in European populations. Nat Genet 1994, 7:169-175

28. Wiuf C: Do delta F508 heterozygotes have a selective advantage? Genet Res 2001, 78:41-47.

29. Mateu E, Calafell F, Ramos MD, Casals T, Bertranpetit J: Can a place of origin of the main cystic fibrosis mutations be identified? Am J Hum Genet 2002, 70:257-264.

30. Alfonso-Sanchez MA, Perez-Miranda AM, Garcia-Obregon S, Pena JA: An evolutionary approach to the high frequency of the Delta F508 CFTR mutation in European populations. Med Hypotheses 2010, 74:989-992.

doi:10.1186/1750-1172-6-74

Cite this article as: Beech et al: Ancient founder mutation is responsible for Imerslund-Gräsbeck Syndrome among diverse ethnicities. Orphanet Journal of Rare Diseases 2011 6:74.

\section{Submit your next manuscript to BioMed Central and take full advantage of:}

- Convenient online submission

- Thorough peer review

- No space constraints or color figure charges

- Immediate publication on acceptance

- Inclusion in PubMed, CAS, Scopus and Google Scholar

- Research which is freely available for redistribution

Submit your manuscript at www.biomedcentral.com/submit
Biomed Central 